\title{
Reflexões acerca da política de segurança nacional: alternativas em face das mudanças no Estado*
}

\author{
Octavio Penna Pieranti** \\ Fabio dos Santos Cardoso*** \\ Luiz Henripue Rodriques da Silva****
}

SuMÁrio: 1. Introdução; 2. O papel do Estado brasileiro; 3. A política de segurança nacional durante o regime militar; 4. As Forças Armadas e a segurança nacional após a redemocratização; 5 . Conclusão.

SUMMARY: 1 . Introduction; 2. The role of the Brazilian state; 3 . National security during the military regime; 4 . The Armed Forces and national security after redemocratization; 5 . Conclusion.

Palavras-chave: políticas públicas; segurança nacional; defesa nacional.

KEY WORD S : public policies; national security; national defense.

As transformações sofridas pelo Estado brasileiro têm sido parte integrante do debate político e acadêmico do país desde o período da redemocratização na década de 1980. Este debate, porém, não leva freqüentemente em conta uma atribuição fundamental do Estado - a segurança nacional. O papel de promover e garantir a segurança nacional é monopólio do Estado-

\footnotetext{
* Artigo recebido em maio e aceito em dez. 2005.

** Jornalista e mestrando em administração pública na Ebape/FGV. Endereço: Ebape/FGV Praia de Botafogo, 190, 5o andar - Botafogo - CEP 22250-900, Rio de Janeiro, RJ, Brasil. E-mail: Octavio.Pieranti@fgv.br.

*** Administrador de empresas, funcionário dos Correios e mestrando em administração pública na Ebape/FGV. Endereço: Rua Barão de Mesquita, 380, ap. 707 — Tijuca — CEP 20540-003, Rio de Janeiro, RJ, Brasil. E-mail: Fabio.Cardoso@fgv.br.

**** Administrador de empresas, capitão da Marinha brasileira e mestrando em administração pública na Ebape/FGV. Endereço: Rua Major João Gualberto Braga, 695 - Campo Grande CEP 23092-520, Rio de Janeiro, RJ, Brasil. E-mail: luizmestradofgv05@yahoo.com.br.
} 
nação desde sua origem no século XVII. Apesar dessa relevância, a questão da segurança nacional ocupa posição secundária nas agendas dos meios políticos brasileiros. Este artigo discute, por meio de uma pesquisa documental, o desempenho do Estado brasileiro na elaboração de uma política de segurança nacional, considerando seu contexto histórico. Findo o regime militar, constata-se a inexistência de uma política de segurança nacional clara, seja por uma inoperância dos atores ligados à política partidária, seja por um lócus aberto e ainda não preenchido no processo de redefinição do papel das Forças Armadas.

\section{Reflecting on national security policies: alternatives considering State changes}

Since the mid-1980s politicians and academicians have been debating the transformations in the Brazilian state. This discussion, however, frequently does not take into account a basic attribution of the state: national security. The role of promoting and guaranteeing national security is a monopoly of the nation-state since its origin in the 17th century. Despite their relevance, national security issues have a secondary role in the Brazilian political agenda. This article discusses, based on a documental research, the performance of the Brazilian state in the elaboration of a national security policy, considering the historical context of this country. Since the end of the military regime the absence of a national security policy has been evident, due either to inefficient political actors or to an undefined role of the Armed Forces.

\section{Introdução}

Desde 1988, a Constituição Federal redefiniu o papel das Forças Armadas e sua participação na administração pública brasileira. A nova Carta Magna revisou não apenas o papel dessas estruturas, como também forçou reformulações na política de segurança nacional, ora posta em prática por um regime democrático. Este artigo analisa essa política, tendo em vista a relação entre a sociedade civil, o Estado e as Forças Armadas. Para isso, serão utilizadas fontes documentais diversas, entre as quais, a legislação brasileira, livros e periódicos acadêmicos, que discutem a concepção contemporânea de segurança nacional e o entendimento sobre o tema a partir de décadas anteriores.

Segundo Hart (1982), há uma necessidade prática de se adaptar a estratégia militar à natureza da política do Estado que a emprega. No Brasil, a política de segurança nacional é formulada pelo Poder Executivo, porém requer uma cooperação do Poder Legislativo quanto à disponibilidade de recursos orçamentários. Esse cenário leva a duas mudanças a partir da Constituição Federal de 1988. A primeira, a participação da sociedade civil, por meio de seus repre- 
sentantes legais, e do Estado, na determinação do que deveria ser a segurança nacional para o Brasil e sua soberania. A segunda seria o comprometimento desses dois poderes da República com os recursos necessários - financeiros, materiais e humanos - para a execução dessa política. Ao atribuir novas responsabilidades a atores distintos, a Constituição Federal redefine a discussão sobre a segurança nacional, considerada, durante toda a história da República, de responsabilidade dos militares, já que são eles que, em tese, estudam e debatem o assunto com mais profundidade.

Na seção 2 deste artigo, é mostrado um retrospecto das modificações por que passou o Estado brasileiro, por meio da apresentação de conceitos relevantes que o definiram. Sua importância é apresentar a estrutura conceitual em que se inserem hoje as Forças Armadas e os principais desafios a serem enfrentados para uma mudança de concepção no emprego do efetivo militar.

O conceito de política de segurança nacional que norteou todo o período do regime militar é discutido na seção seguinte. Essa concepção está estreitamente ligada à interpretação feita, ainda na década de 1950, por Golbery do Couto e Silva, ator importante no desenrolar da história do Brasil nos anos seguintes. Golbery ocuparia postos de destaque na cúpula da administração pública, influenciando em muito a concepção de segurança nacional posta em prática durante o regime militar.

A quarta seção deste trabalho traz uma abordagem do relacionamento, durante os últimos 20 anos, entre as Forças Armadas e o Estado. A redemocratização do país e a conseqüente promulgação de novo aparato legal culminaram com a reestruturação das Forças Armadas, a criação do Ministério da Defesa e as alterações na política de segurança nacional.

Na conclusão é interpretado o papel desempenhado pelos atores no tocante à política analisada, dentro da estrutura conceitual que caracteriza o cenário político atual brasileiro. Constata-se a necessidade de se consolidarem novas definições relativas à segurança nacional, bem como a implementação da política para esse setor.

\section{O papel do Estado brasileiro}

Desde a assinatura do Tratado de Westfália de 1648, o Estado possui atribuições exclusivas como o monopólio do uso da força e o estabelecimento e manutenção da ordem e paz social. Mas, segundo Mello (1999) e Magnoli (2004), do século XVII até os dias atuais, o Estado tem sofrido diversas transformações no que se refere às suas atribuições e atividades junto à sociedade. 
Tais modificações refletem-se na redução do poder econômico e político do Estado, considerado ente soberano.

No cenário brasileiro é possível identificar a existência de um Estado nacionalista entre as décadas de 1930 e 1950, durante o governo Getúlio Vargas (Guimarães, 2001). Nesse período, cabia ao Estado atender as principais demandas da sociedade, mantendo suas características essenciais, como a manutenção da segurança pública e nacional em conjunto com as atividades inerentes ao serviço público, tais como saúde e educação. Além dessas atribuições, também cabia ao Estado promover a formação de uma indústria de base nacional que possibilitasse o desenvolvimento econômico do país, mediante a substituição de importações.

Remonta a esse período a primeira reforma do Estado brasileiro (Bresser-Pereira, 2001), com a criação e desenvolvimento de uma estrutura burocrática clássica voltada para um suposto melhor funcionamento do aparelho governamental brasileiro, na qual se destacava o Departamento de Administração do Serviço Público (Dasp), fundado em 1938. Ainda no governo Vargas, a criação de empresas estatais como a Companhia Siderúrgica Nacional (CSN) em 1941 e o Petróleo Brasileiro S/A (Petrobras) em 1953 reforçaram o caráter nacionalista vigente que, segundo Werneck (2001), buscava promover o protecionismo da indústria brasileira e os investimentos estatais em infra-estrutura.

Destaque-se que, nessa época, as questões orçamentárias e relativas a gastos públicos eram centralizadas pelo Poder Executivo. Apenas entre 1945 e 1954 o Poder Legislativo passa a dispor de limitada participação na elaboração do orçamento federal, permanecendo, como responsabilidade do presidente da República, a decisão de como e quando seriam feitos os gastos públicos.

Com a ascensão de Juscelino Kubitschek (JK) à Presidência da República em 1958, o Estado brasileiro passa a adotar um caráter desenvolvimentista com base no capital externo e pautado, assim, na abertura do mercado nacional para o ingresso de empresas estrangeiras, principalmente no setor automobilístico. A política estatal durante o governo JK promoveu a criação de entidades públicas que proporcionassem o desenvolvimento industrial privado nos âmbitos regional e nacional. É criada, nesse período, pela Lei $\mathrm{n}^{0} \mathrm{3.692}$, de 15 de dezembro de 1959, a Superintendência de Desenvolvimento da Região Nordeste (Sudene - Ministério da Integração Nacional, 2005). Além dessa realização, outras ações, como as obras de construção de boa parte da malha viária interestadual, datam desse período. É também entre o fim da década de 1950 e início da de 1960 que o BNDES assume papel de destaque no fomento de projetos de modernização e desenvolvimento da economia brasileira. O governo JK possuiu, ainda, como traço marcante, a continuidade do distanciamento entre os 
poderes Executivo e o Legislativo no processo de tomada de decisões políticas. Parcelas significativas das decisões governamentais eram tomadas com base em propostas dos grupos de trabalho que assessoravam o presidente da República naquele governo.

Com a ascensão do regime militar em 1964, o Estado brasileiro, segundo Diniz (2001), mantém-se na rota do desenvolvimentismo, contudo esse é de caráter diferenciado do que havia sido praticado pelo governo JK. Para Moura (2001), nesse período é verificada uma associação do Estado privatizado com o grande capital nacional e estrangeiro. Essa associação seria a fomentadora do desenvolvimento nacional, cabendo ao Estado prover a infraestrutura necessária para a atuação do capital privado. Seria também atribuição do Estado atuar em setores econômicos considerados estratégicos para o país no que se refere à segurança nacional. Remonta a esse período a criação de empresas estatais nos setores de mineração, telecomunicações e energia elétrica. Verifica-se, também, a centralização das decisões referentes a assuntos estatais unicamente no Poder Executivo, responsável por aprovar e determinar o orçamento do governo federal para cada ano. As práticas estatais centralizadoras e desenvolvimentistas do governo militar resistiram até meados da década de 1980, quando perderam intensidade no cenário nacional.

Com o início do governo de José Sarney em 1985, o Estado brasileiro começou a sofrer um processo de reforma e revisão do seu papel perante a sociedade. Este processo tem início, devido à influência das mudanças ocorridas na Grã-Bretanha e EUA, respectivamente nos governos de Margaret Thatcher e Ronald Reagan, no que se refere à mudança de um Estado promovedor de bem-estar social (welfare) para um Estado com estrutura mínima, cujas ações seriam de cunho regulatório, normativo e tributário.

Data de meados da década de 1980, durante o período da redemocratização brasileira, o início do debate sobre quais seriam as atribuições do Estado, bem como a necessidade de redefinir os gastos públicos. Na visão de Bresser-Pereira (2001), esse debate sofreu retrocessos, como o ocorrido com a promulgação da Constituição de 1988, que retomou a visão burocrática estatal da década de 1930 e permeou os três poderes da República nos governos Sarney (1985-90), Collor (1990-92) e Itamar Franco (1992-94). Com a decretação do Plano Real em 1994, o discurso predominante no mercado e no governo federal referia-se à necessidade de cortes nos gastos públicos como um dos meios de estabilização econômica.

As reformulações sofridas pelo Estado nas últimas décadas são temas discutidos por Mitchell e Simmons (2003:151), que afirmam que o processo político sofre ineficiências na sua execução. Elas ocorrem devido aos políticos, que buscam adotar práticas que possibilitem sua manutenção em cargos 
públicos, mediante a barganha de votos. Juntamente com essa barganha, os gastos públicos são baseados em uma incoerência de alocação de recursos, nos quais custos são separados de benefícios. Assim, a sociedade tem seus recursos captados mediante impostos de maneira dispersa, financiando gastos públicos que pouco a beneficiam. Há, segundo os autores, concentração de benefícios para alguns e dispersão de custos para outros. Daí, o governo incorre no erro de gastos públicos inadequados, empregando dinheiro de impostos em projetos nos quais os custos de implantação são superiores aos benefícios obtidos pela sociedade. Tais práticas sobreviveriam por serem eficientes mecanismos de obtenção de voto.

Para encerrar ou ao menos minimizar essas "patologias políticas" - assim chamadas por Mitchell e Simmons (2003) - que assolavam o governo brasileiro, Fernando Henrique Cardoso (FHC), em 1995, assume a Presidência da República, com uma agenda política na qual estava contida a reforma do aparelho de Estado brasileiro. Essa reforma propunha ajuste fiscal mediante a redução de gastos públicos, bem como a orientação das ações governamentais na busca de eficiência e de modernidade (Bresser-Pereira, 2001).

Tem início no segundo mandato de FHC (1998-2002) a reforma do aparelho de Estado, que buscava adaptar o conceito de Estado mínimo, no qual só deveria ser estatal o que não pudesse ser regulado pelo mercado. Essa reforma, segundo Bresser-Pereira (2001), ministro responsável pelas mudanças, tinha como objetivo prover o Estado brasileiro de uma visão gerencial, na qual suas ações fossem orientadas por resultados e os funcionários públicos trabalhassem por metas, possibilitando, assim, o fim do patrimonialismo presente em práticas clientelísticas e fisiológicas.

É possível verificar que, durante o período democrático que se seguiu à promulgação da Constituição de 1988, todos os presidentes buscaram acatar a determinação legal de que o orçamento anual da União deveria ser definido mediante aprovação pelo Congresso Nacional de proposta enviada pelo chefe do Executivo. Com isso, o orçamento federal vem, a cada ano, sendo definido em função de diferentes agendas políticas de atores distintos, que incorrem no risco de desconsiderar gastos com áreas de atuação exclusivas do Estado, tais como segurança e defesa pública, em função da redução e austeridade nos gastos públicos.

\section{A política de segurança nacional durante o regime militar}

O Estado brasileiro ainda começava a ser marcado pelo ideário desenvolvimentista, quando a temática da segurança nacional já era discutida com mais inten- 
sidade dentro das unidades militares. A primeira edição do livro Planejamento estratégico foi lançada em 1958, quando a Biblioteca do Exército decidiu reunir as conferências apresentadas pelo então coronel Golbery do Couto e Silva nos cursos da Escola Superior de Guerra (ESG) desde 1952. Menos de oito anos depois do lançamento do livro, as idéias do já general começariam a ser postas em prática, graças à mudança de regime e à notoriedade atingida pelo autor. O livro tornou-se, então, não só referência obrigatória para a compreensão da interpretação do conceito de segurança nacional durante o regime militar, como também peça fundamental para se repensar o mesmo conceito.

A importância de Golbery para o cenário político brasileiro começou a se tornar evidente em 1964, depois de ter sido, dois anos antes, transferido para a reserva pelo presidente da República, João Goulart. No governo Castello Branco, o primeiro do regime militar, Golbery planejou, criou e assumiu o Serviço Nacional de Informações (SNI), colocando em prática idéias defendidas nas conferências na ESG e no Conselho de Segurança Nacional, onde serviu em 1961. Depois de se afastar da cúpula do poder federal durante o governo Costa e Silva, quando se tornou consultor e posteriormente presidente da Dow Química no Brasil, Golbery voltou a ter influência em setores da administração pública com a chegada de seu amigo e general Ernesto Geisel à presidência da Petrobras no governo Medici. Depois de Geisel assumir outra presidência, a da República, Golbery tornou-se chefe do Gabinete Civil, posto em que se manteve também durante parte do governo Figueiredo. Golbery do Couto e Silva faleceu em 1987.

Mais que Golbery, chegou ao poder nas décadas de 1960 e 1970 a geração que, nos anos 1950, despontava na ESG. A partir de 1952, Ernesto Geisel também proferiu palestras na escola. A boa relação entre esses militares, refletida nos convites feitos a Golbery para que assumisse altos cargos no governo federal, permite concluir uma concordância em conceitos cruciais, como o da segurança nacional. Assim, a exposição feita nesta seção, ao se basear principalmente no livro Planejamento estratégico, discute interpretação razoavelmente comum à parte dos governantes militares do conceito de segurança nacional. Não por coincidência, Golbery foi incumbido de colocá-lo em prática.

Segurança nacional, sob a ótica de Golbery, significa a destruição de possíveis ameaças à rotina da sociedade, ao funcionamento do Estado e à vida dos governantes. A flexibilidade desse conceito facilita interpretações diversas. Cabia ao governante a decisão de que postura adotar, diante dos perigos que também ele era o responsável por reconhecer. A segurança nacional estaria, dado seu caráter coletivo, acima de direitos individuais e comportamentos privados, passíveis de supressão quando necessários. Golbery (Silva, 1981:22-23) insistia na preponderância do Estado e, conseqüentemente, de seus chefes em momentos de ameaça à segurança nacional: 
não há de fato - nem poderia haver em sã consciência — quem negue no governo a responsabilidade total e, pois, o direito incontestável de agir, orientando, mobilizando, coordenando, para tal fim, todas as atividades nacionais. E a concentração maior de poder que daí resultar, em mãos dos delegados da vontade do povo, a ampliação da esfera de atribuições reservada ao Poder Executivo, as restrições impostas aos próprios direitos de cidadania na forma prevista nos textos constitucionais são corolários iniludíveis de toda situação de reconhecida gravidade para a segurança nacional - a aplicação de tais corolários comportando, como é evidente, grande margem de flexibilidade que lhes permita convenientemente adequar-se ao progressivo aumento ou relaxação das tensões externas ou internas que se estejam a manifestar.

Justificava-se, pois, qualquer atitude do governo, se posta em prática em prol da segurança nacional. Dever-se-ia evitar a guerra, mas, caso necessário, não se poderia hesitar em empreendê-la. Guerra, como frisava Golbery, incluía confrontos externos e internos, já que, no mundo marcado pela Guerra Fria, ameaças externas e internas confundiam-se. Para o general, movimentos de contestação armados que defendiam o comunismo não diferiam em nada de ameaça externa, já que seriam "poderosa quinta-coluna agindo, tanto prévia como simultaneamente, sempre em estreita coordenação com quaisquer planos de agressão arquitetados no Kremlin" (Silva, 1981:41). Existia, portanto, base teórica que explicava a formação de amplo aparato de repressão a opositores do regime vigente. No Brasil, ao Centro de Informações da Marinha (Cenimar), único órgão de informações das Forças Armadas existente antes de 1964, juntaram-se o Centro de Informações do Exército (CIE), o Centro de Informações e Segurança da Aeronáutica (Cisa) e, em 1967, o SNI de Golbery (Antunes, 2002).

Para garantir a segurança nacional, o Estado precisava planejá-la, colocando em prática uma política de segurança nacional, demandando que objetivos e metas fossem claramente definidos. Golbery separava-os em dois grupos. O primeiro reunia os objetivos nacionais permanentes (ONP), de caráter eminentemente político, abrangendo interesses e aspirações constantes do país e sendo, portanto, essenciais para a sobrevivência da nação sem ameaças ao seu fracionamento. Esses objetivos estavam amparados em pelo menos três condições básicas, segundo Golbery - autodeterminação, integração crescente e prosperidade. Tratava-se, pois, de planejamento capaz de ser empreendido apenas pela alta cúpula da administração pública e de interesse fundamental para o chefe de Estado.

O segundo grupo abrangia os objetivos nacionais atuais (ONA). Ainda que a nomenclatura adotada por Golbery remeta esses à conseqüência de pro- 
blemas pontuais, determinados por análises conjunturais, os ONA têm função outra e mais ampla, segundo ressalva feita pelo próprio autor. Esses objetivos "referem-se exclusivamente aos antagonismos que se identificam, seja no campo interno, seja no campo internacional, contrários à desejada consecução daqueles objetivos nacionais permanentes" (Silva, 1981:28-29). Era necessário, assim, ter em mente e perseguir sempre os ONP, constituindo-se outros objetivos em peças intermediárias para que eles fossem atingidos.

A política de segurança nacional dependia de um entendimento pleno do que Golbery chamou de poder nacional e potencial da nação, funções intimamente interligadas. Somente se o Estado fosse capaz de trabalhar de forma apropriada o potencial do país em setores econômicos diversos, o poder nacional - entendido, aí, como resultado dos setores político, bélico e econômico se fortaleceria. Para isso, fazia-se necessário reconhecer o Estado como planejador da economia nacional e dos investimentos que dela decorrem.

Essa era situação imprescindível na definição de Golbery, sequer discutida ou posta em dúvida. Para o general, cabia ao Estado apostar no crescimento econômico, sem se descuidar de fundamentos outros ligados ao fortalecimento do poder nacional. Ao analisar especificamente o caso do Brasil ainda em 1954, Golbery (Silva, 1981:25) reforçava a importância da economia e de seu crescimento para o desenvolvimento nacional:

o que mais está a segurança nacional a exigir, num país do tipo do nosso, é sobretudo a ampliação de nossa infra-estrutura econômica, a redução dos pontos de estrangulamento de nossa economia tão desordenadamente evolvida, a atenuação pelo menos dos graves desequilíbrios existentes entre seus diversos setores básicos - objetivos todos, por certo, de alta essencialidade em qualquer programa de desenvolvimento econômico-social.

O Estado-modelo a ser adotado, segundo Golbery, teria de ser forte e regulador de diversos setores não apenas porque dele dependia a garantia da segurança nacional, como também porque a segurança nacional dependia de um nível reduzido de oposição, de um planejamento centralizado e de crescimento econômico. Não seria aceitável, assim, que o Estado partilhasse com a iniciativa privada funções essenciais à segurança nacional.

Exemplo de setor claramente atrelado à lógica da segurança nacional durante o regime militar são as comunicações. A Lei $\mathrm{n}^{0}$ 2.597, de 1955, reconheceu o que há muito já era fato indiscutível para os militares: os meios de comunicação são de interesse para a segurança nacional. Décadas antes, as Forças Armadas começaram a se preocupar com esse setor. O estudo desse 
campo rendeu a quadros militares posição de destaque em órgãos reguladores e fiscalizadores.

Prova dessa atuação é a participação das Forças Armadas na Comissão Técnica de Rádio (CTR), responsável por regular a radiodifusão brasileira de 1931 a 1962: dos três membros da comissão, dois eram indicados pelos ministérios militares e seu presidente sempre foi um oficial. No Conselho Nacional de Telecomunicações (Contel), criado depois da promulgação do Código Brasileiro de Telecomunicações em 1962, os militares ocupavam quatro das 10 cadeiras. Criado em 1967, o Ministério das Comunicações também contou com ampla presença de militares. Ainda que o ministro Carlos Simas, o primeiro escolhido para comandar as comunicações, não fosse militar, seus assessores e subordinados eram. Dos 16 funcionários que compunham a ainda pequena estrutura do Ministério das Comunicações no governo Costa e Silva, 11 eram militares - ou seja, 68,75\% dos funcionários do Ministério das Comunicações pertenciam aos quadros das Forças Armadas, em um governo em que a ocupação por militares de cargos destinados a civis era, em média, de $12 \%$ (Mathias, 1999).

A administração de um setor ligado à segurança nacional não demandava apenas a preparação de quadros tecnicamente especializados. Requeria, como demonstrado pela análise das conferências de Golbery, ampla participação e atenção do Estado e das Forças Armadas. Assim, aliada a uma política de crescimento econômico, os governos militares promoveram uma reformulação das comunicações no Brasil. Para isso, criaram diversas empresas estatais, como a Embratel, a Telebrás e a Radiobrás, todas no âmbito da administração pública federal. Ao longo do regime militar, membros das Forças Armadas assumiram os principais cargos dessas empresas e do Ministério das Comunicações. Assim, o Estado regulava setor fundamental à segurança nacional.

As comunicações não eram apontadas como de interesse para a segurança nacional apenas pela legislação vigente. Militares abertamente expunham a importância desse setor em discursos e mensagens oficiais.

Em processo de investigação da fundação da TV Globo, na década de 1960, ao menos dois militares, por exemplo, deixaram clara sua preocupação com a possibilidade de associação de uma emissora nacional ao capital estrangeiro, portanto não ligado à lógica da segurança nacional. Manifestavamse em relação aos ataques feitos pelo deputado federal e diretor dos Diários Associados, João Calmon, principal crítico do acordo envolvendo a TV Globo e o grupo norte-americano Time-Life.

O comandante do III Exército, general Justino Alves Bastos, enviou a João Calmon, no dia 14 de abril de 1966, a seguinte mensagem: "Estou certo de que a vigilância do governo do marechal Castello, bem como a patriótica 
pregação do nobre deputado, evitarão as ameaças reveladas por Vossa Excelência e tramadas dentro e fora do nosso território" (Herz, 1988:166-167). Mais enfático foi o general Peri Bevilácqua, ministro do Superior Tribunal Militar, em entrevista concedida aos Diários Associados (Herz, 1988:167):

\begin{abstract}
É fora de dúvida que essa intromissão e conseqüente influência alienígena sobre a opinião pública comprometem a segurança nacional. É um caso de polícia. É um atentado frontal à Constituição dos Estados Unidos do Brasil. Não apenas a Constituição, mas também o Código Brasileiro de Telecomunicações é violentado, quando estrangeiros indesejáveis são admitidos em parceria por brasileiros esquecidos do seu dever de obediência à lei do país e à organização de telecomunicações que lhes foram concedidas pelo Estado.
\end{abstract}

Findo o regime militar, o conceito de segurança nacional foi reinterpretado. Não bastasse sua proximidade com as Forças Armadas, ora deixando os principais cargos do governo federal, a interpretação ainda vigente dependia de um Estado então em processo de intensa mudança.

\title{
4. As Forças Armadas e a segurança nacional após a redemocratização
}

O processo de adequação das relações civis-militares, durante o período de redemocratização, foi marcado por uma lenta adaptação ao novo contexto político. A insegurança era a tônica, pois se tinha receio quanto a possíveis retrocessos que poderiam pôr a definhar o recém-iniciado processo de implantação da democracia. Esse foi um dos principais fatores que permitiram aos militares um grande espaço de atuação na condução inicial do país, no período que se estendeu de 1985 até o início do governo Collor.

Como expõe Fiori (1995), ao retornarem do exílio, após o processo de anistia política, intelectuais progressistas traziam o desejo de colocar em prática os frutos de vários anos de reflexão histórica e teórica. Passaram, entretanto, o resto da década de 1980 presos em discussões, divididos entre os que defendiam a simples redemocratização política, o que implicitamente trazia a manutenção da estrutura vigente até aquele momento, e os que construíam estratégias de estabilização econômica e de redistribuição da renda. O retardo na escolha de políticas a serem implantadas também contribuiu em muito para a lenta transição entre o regime militar e o governo civil, que assumia o poder àquela época. 
Essa transição foi pactuada pelas elites, com grande influência militar, interferindo no processo de recondução democrática, na definição de cronogramas e nos resultados a serem alcançados, o que configurou, conforme defende D’Araujo (2000), um processo de democratização pelo alto. Tal postura preservou os militares da radicalização dos debates, no âmbito político-partidário, sobre a sua inserção no novo regime, mas afastou também a possibilidade de mudanças mais substantivas na reordenação constitucional da função das Forças Armadas (Oliveira e Soares, 2000). A democratização adotada e a forma de tratamento do assunto segurança nacional - termo que, como convém lembrar, ficou pejorativamente relacionado às ações repressivas do regime militar - no início de governo civil, em grande parte, refletiam a visão de planejamento estratégico do general Golbery, disseminada dentro da alta hierarquia do Exército, como já visto.

Contribuindo para a permanência dessa visão de segurança nacional, fatores outros devem ser considerados. Entre eles, as teorias da inexistência de risco iminente e da tradição jurídica brasileira, como são chamadas por Oliveira e Soares (2000), são hipóteses relevantes que se complementam. Delas se obteve o seguinte resultado: alguns parlamentares brasileiros não reconheceram, em discursos e proposições, uma prioridade às questões militares, por inexistirem ameaças evidentes de guerra. Não havendo ameaças, ou se não são percebidas como tais, elas não podem ganhar contornos políticos e, portanto, não ganham importância entre os partidos e os eleitores. Por não fazerem parte das preocupações de curto e médio prazos do ambiente político e não darem votos aos candidatos nem aos partidos, os temas militares não integram as agendas eleitorais e não chegam até a opinião pública. Atuar na temática militar não representa ganhos na dinâmica eleitoral, como constataram Oliveira e Soares (2000). Outro fator é o procedimento adotado pela sociedade civil e pelos poderes Executivo e Legislativo, que relegam o aparelho militar ao seu próprio cuidado, como se o fato de se discutir temas militares fosse um pecado contra a postura supostamente pacífica e cordata do povo brasileiro.

A necessidade de se redefinir a função e o papel dos militares tornou-se mais evidente no contexto do processo constituinte, durante os trabalhos da Comissão Afonso Arinos, que apontavam a presença e a continuidade das prerrogativas militares como um dos problemas a serem resolvidos pelos setores empenhados em consolidar a democracia. Terminado o regime militar e promulgada a nova Constituição Federal em 1988, ficou evidente a impossibilidade de existência de um Estado como o imaginado por Golbery. A Carta Magna era clara e rigorosa em relação à obrigatória manutenção dos direitos individuais apresentados majoritariamente em seu art. $5^{\circ}$. Mesmo a decreta- 
ção dos estados de defesa e de sítio, previstos em momentos de ameaça à soberania nacional, teria que ser apreciada por diferentes órgãos e ocupantes de cargos na administração pública, ficando reduzida a margem de manobra do presidente da República.

No seio das Forças Armadas, as mudanças já eram sentidas e já se começava a experimentar uma fase de crescentes exigências de adaptação, após 21 anos de permanência no centro do poder político. As mudanças ideológicas do mundo no pós-Guerra Fria e as condicionantes internas relativas à consolidação da democracia sugeriam ou mesmo impunham às Forças Armadas uma redefinição de seu papel político.

A extinção do Serviço Nacional de Informações (SNI) pelo presidente Fernando Collor de Mello pode ser considerada como marco inicial de uma lenta e, por vezes, descontínua elaboração de um novo perfil nas relações entre civis e militares. A recessão econômica, que marcou profundamente os governos civis, atingiu também orçamentos e salários militares. A preocupação central das Forças Armadas passou a ser a sua sobrevivência em face da nova Constituição Federal, que determinou que os gastos orçamentários passariam a ser apreciados pelo Congresso Nacional.

Ao ocorrer a crise de governabilidade do governo Collor, motivada por inúmeros escândalos, a sociedade civil mostrou-se receosa quanto à possibilidade de uma nova intervenção militar, tendo em vista a atitude sempre agressiva do presidente da República no trato com as Forças Armadas e a forma como cuidou dos assuntos atinentes à segurança nacional. Entretanto, os militares se mantiveram neutros, deixando para as esferas políticas a condução do processo de impeachment. Esse processo serviu, segundo D'Araujo (2000), de prova de fogo para os militares na nova democracia, pois mostrou o respeito e a obediência à Constituição que passaram a nortear as suas ações. Mostrou também, como frisa Huntington (1996), mesmo que de forma rudimentar, a possibilidade real de se consolidar o controle civil objetivo. Tal controle é a maximização do profissionalismo militar, por meio de uma distribuição de poder político entre grupos militares e civis, e atinge o seu fim ao militarizar os militares, tornando-os instrumento do Estado e afastando as Forças Armadas definitivamente da política partidária (Huntington, 1996).

Como visto anteriormente, as políticas macroeconômicas do governo Fernando Henrique Cardoso trouxeram para o contexto brasileiro o conceito de Estado mínimo e formularam a política administrativa contida no Plano Diretor da Reforma do Aparelho de Estado. As Forças Armadas, atentas às tendências de mudança, viram no novo conceito e em suas implicações a oportunidade de promover a sua própria adaptação ao novo cenário brasileiro externo e interno. 
Por iniciativa dos chefes militares, esses conceitos e as ferramentas gerenciais neles contidas foram aplicados principalmente às atividades administrativas, com ênfases diferentes em cada força, buscando a eficiência e a eficácia nos processos, a transparência nos atos e a redução da estrutura a um meio-termo entre a que as restrições orçamentárias permitiam e a que era vista como ideal para os objetivos traçados pelos militares. E essas ações surtiram um grande efeito sobre a administração do contingente militar, refletida, por exemplo, na aplicação dos conceitos de qualidade e análise e melhoria de processos, a fim de permitir a redução dos gastos com burocracia. Houve, também, a implantação nas Forças Armadas de conceitos reformadores, principalmente por se tratarem de estruturas organizacionais militares, como o das organizações militares prestadoras de serviço (OMPS), a partir de 1994, e do Contrato de Autonomia de Gestão, em 1999. A sistemática das OMPS foi a solução desenvolvida pela Marinha para tratar de sua incapacidade em avaliar os custos dos serviços prestados e produtos desenvolvidos pelas organizações prestadoras de serviços industriais (OMPS-I), de saúde (OMPS-H), de abastecimento (OMPS-A), de ciência e tecnologia (OMPS-C) e especiais (OMPS-E), que englobariam as organizações de ensino e bases navais, e para determinar a necessidade estratégica de suas existências. Já o Contrato de Autonomia de Gestão, aplicado experimentalmente em apenas duas OMPS, foi a adaptação do conceito de administração por objetivos, contido nas agências executivas e organizações sociais, à estrutura presente nas OMPS. A Lei $\mathrm{n}^{\mathrm{o}}$ 9.724, de $1^{\underline{0}}$ de dezembro de 1998, e o Decreto no 3.011, de 30 de março de 1999, vieram respaldar legalmente essas iniciativas, agraciadas com dois prêmios Hélio Beltrão pela inovação que representaram para a gestão pública. Todas essas ações refletiam, em última instância, o desejo das instituições de se inserirem definitivamente na estrutura do Estado democrático em fase de consolidação e de elevarem a temática da segurança nacional ao patamar de outros temas de relevância para o país.

A despeito de todo o esforço, as restrições orçamentárias continuaram fortemente presentes e crescentes, impostas pelos principais gestores econômicos dos governos democráticos que se seguiram, os quais, aparentemente, como nos sugerem Soares e Oliveira (2000), não eram dotados de uma visão de longo prazo sobre questões estatais e nacionais, entre as quais se incluíam as demandas militares. Essa situação levou os ministros militares a reivindicarem junto ao governo uma maior atenção às necessidades orçamentárias, por sentirem estar no limite do aperto orçamentário, enfrentando cortes profundos nos investimentos e com repercussões nos custos correntes.

Essa discussão foi o catalisador que levantou novamente o questionamento quanto à participação da sociedade civil e do Estado no estabelecimen- 
to do que seriam as prioridades para a segurança nacional brasileira. É, também, um dos pilares fundamentais do controle civil objetivo, pois é esse embate de idéias, obedecendo aos ditames constitucionais, que leva à maturidade no relacionamento entre civis e militares, onde o Estado, que tem de ser o representante da vontade do povo em uma democracia, definiria o que quer das Forças Armadas, dando a elas os meios necessários para atingir as metas. Deve-se, entretanto, entender que uma política de segurança nacional não sobreviveria subordinada a mudanças radicais na política do governo, em ciclos de quatro anos, que poriam a perder investimentos já iniciados e esforços de adaptação já realizados pelas forças. À segurança nacional é imprescindível que haja estabilidade nos compromissos assumidos.

A primeira etapa dessa discussão foi a definição da Política de Defesa Nacional, assim chamada a política de segurança para o Brasil. Como nos dizem Oliveira e Soares (2000), em respeito à exclusiva relação de comando do presidente da República sobre as Forças Armadas, ele foi a única autoridade responsável por aquele documento. Conforme nos acrescentam ainda os dois autores, o Poder Legislativo foi mantido alheio de qualquer participação efetiva e formal. No entanto, é possível vislumbrar, no texto, um quadro de co-responsabilidade nascente nas atribuições do Congresso Nacional.

A segunda etapa foi a criação do Ministério da Defesa, que pode ser considerado como um ponto de inflexão importante, por se tratar de um mecanismo institucional que amplia as possibilidades do estabelecimento do controle civil objetivo. A participação civil na estrutura organizacional do ministério é bastante ampla, sendo prevista em praticamente todos os cargos que definem os grandes rumos da defesa no país.

Apesar dos avanços alcançados no relacionamento entre civis e militares, o debate sobre a defesa nacional não pode ser considerado findo, pois dele depende o compromisso da sociedade e do Estado quanto a esse assunto e a compreensão da importância da destinação de recursos para esse fim. O almirante Mario César Flores (2000), ex-ministro da Marinha no governo Collor, alerta que, dentro de um quadro de restrições orçamentárias e de desajustes internos potencialmente mais indutores de insegurança do que o externo, as Forças Armadas devem proceder a uma revisão prudente, não-radical, do sistema militar, sem ufanismos ou melindres. Defesa da soberania do território, incluindo-se as fronteiras terrestres e fluviais e águas jurisdicionais, atuação em grandes extensões oceânicas e em cruzadas internacionais, Amazônia, tamanho, preparo e aparelhamento das forças e a atuação em distúrbios internos caracterizam-se, nessa linha, como alguns pontos que precisariam deixar de ser assunto restrito à ótica militar e passar pelo crivo das opiniões da sociedade e do governo que a representa. Entretanto essa revisão 
se torna complicada, devido ao quadro de apatia política e social, que impede que se manifeste o que o autor chama de sensibilidade nacional para os assuntos de defesa, com a qual o pensamento estratégico militar brasileiro necessariamente precisa estar alinhado para que direcione corretamente os recursos a serem aplicados e se possa justificar a contrapartida orçamentária exigida pela defesa nacional.

\section{Conclusão}

As transformações na interpretação do papel do Estado nas últimas décadas geraram conseqüências em campos diversos da política brasileira. Entre os setores atingidos pela redução dos investimentos feitos pelo ator estatal, está a segurança nacional. Cortes no orçamento forçaram as Forças Armadas a planejar melhor os seus gastos, apostando em programas de qualidade e na eficiência de seus projetos. Essas medidas refletem, porém, uma tentativa de adaptação ao novo contexto sem aumento da vulnerabilidade da segurança nacional, visto que os cortes contribuíram para a redução do efetivo e para o envelhecimento do aparato bélico. Programas de qualidade, nesse caso, demonstram a necessidade de uma compactação do efetivo militar sem prejuízo de suas funções vitais.

Programas desse tipo apostam, ainda, na conscientização da sociedade civil sobre os problemas referentes à segurança nacional. A certeza de cooperação por parte dela, nesse sentido, baseia-se em um respeito contínuo das Forças Armadas às regras democráticas, desde que findo o regime instalado em 1964, e em uma suposta aproximação entre militares e vários segmentos sociais. Para que isso ocorra, é necessária essa adaptação por parte das Forças Armadas:

Nenhuma sociedade, nenhum poder político responsável se predispõe a defender, a pagar o custo da defesa do que não é percebido como ameaçado. Inexistindo ameaças concretas perceptíveis, este problema só é aliviado ao menos onde não prevalecem autoritariamente valores militaristas de organização política e social - quando o sistema militar é configurado, organizado e dimensionado de tal forma que a sociedade e o poder político o entendam como racional à vista do presente e do futuro imaginável, sustentável sem sacrifícios penosos para o povo.

(Flores, 2000:59) 
Ainda que tenha sofrido mudanças em sua estrutura, o modelo de Golbery, formulado nas décadas de 1950 e 1960, não perdeu, principalmente no que tange às suas premissas, validade. Parte da sobrevivência desse construto deve-se justamente à sua parcial implantação ao longo das últimas décadas. O Estado quase onipresente imaginado por Golbery foi fundamental para o desenvolvimento da economia e, antes disso, para a redução dos pontos de estrangulamento da produção e da distribuição. Assim, quando o Estado diminuiu seus investimentos em infra-estrutura, essa já se encontrava bem mais desenvolvida, se comparada à situação da década de 1950. Trata-se esse aprimoramento de condição fundamental, no modelo de Golbery, para o país reagir a possíveis ameaças contra sua soberania.

Premissa irrefutável de Golbery é, ainda, a importância da participação do Estado na garantia da segurança nacional. Por motivos diversos, cabe ao aparato estatal garantir a soberania da nação e opor-se a ameaças externas. Essa tarefa não poderia ser entregue à iniciativa privada, visto que não se trata de investimento que vise ao lucro e, portanto, sem interesse comercial, bem como são os serviços de inteligência ligados ao Estado os detentores de informações sobre ameaças e as Forças Armadas as responsáveis por planejar e mobilizar o aparato militar. Depende essa estrutura de recursos provenientes do Estado, já que parcerias com o restante da sociedade se dão apenas em momentos pontuais e não geram verba suficiente para o funcionamento das Forças Armadas.

O modelo de Golbery, contudo, ainda que válido, encontra-se atualmente defasado. O Estado, como já demonstrado, afastou-se do planejamento em diversos setores, reduzindo, neles, seu investimento. Empresas estatais, montadas como forma de centralizar o investimento e o planejamento e, portanto, referências nesses setores, foram privatizadas. Ao contrário da situação imaginada por Golbery, o Estado não mais estende sua ação por todas as áreas, o que o impede de, em situações extremas, catalisar todos os recursos da produção para a garantia da segurança nacional. Impede-o, ainda, de agir com plena autonomia para esse fim, já que depende, em parte, da iniciativa privada.

O avanço democrático promoveu outra mudança nesse modelo. Com a promulgação da nova Constituição Federal em 1988, valorizaram-se os direitos individuais em detrimento da possibilidade de ação do Estado indistintamente contra todos. Nesse sentido, foi fundamental a demolição do conceito de "inimigo interno", reprodutor e divulgador, no contexto da Guerra Fria, segundo Golbery, das idéias soviéticas e, por conseguinte, ameaça à soberania nacional. Trata-se, portanto, de conceito confuso, passível de múltiplas interpretações e inibidor de liberdades individuais. Ao garantir direitos indivi- 
duais como cláusulas pétreas, a Carta Magna de 1988 forçou o direcionamento da política de segurança nacional para o inimigo externo e, claro, adaptandoa a um contexto democrático.

Essa mudança essencial do contexto histórico reflete-se na política de segurança nacional não só no momento em que a faz voltar-se para uma possível ameaça externa - muda, também, a percepção sobre a garantia da soberania da nação, aceitando-se que não existe uma guerra permanente, e sim um estado de defesa permanente, capaz de promover respostas por meios militares quando e se for necessário. Para isso, é necessário que se mantenha um aparato militar consistente e um corpo efetivo continuamente treinado - as Forças Armadas dependem, naturalmente, para esse fim, dos recursos destinados e liberados pela cúpula da administração pública.

É possível, portanto, que o Estado privatize suas empresas e afaste-se do planejamento em diversas áreas, entregando-o à iniciativa privada. É possível que o Estado conte com o apoio privado para desenvolver e manter mecanismos ligados à infra-estrutura e à logística. É até possível que o Estado aposte nessa parceria como uma forma salutar de redução de custos, sem prejuízo da eficiência. É possível, ainda, que o Estado opte por diminuir o orçamento de diversos setores. É possível, enfim, que o Estado se aproxime do conceito de Estado mínimo abordado anteriormente.

Essas possibilidades são, entretanto, limitadas. Como a defesa da nação não é atividade econômica que possa ser explorada pela iniciativa privada, cabe ao Poder Executivo garanti-la e ao Poder Legislativo discuti-la e, depois, apoiá-la, o que significa a necessidade de investimentos constantes em recursos humanos, estudos e renovação de aparato militar. A capacidade de adaptação das Forças Armadas ao corte desses elementos é limitada, como também é limitada a possibilidade de redução dos compromissos do Estado em determinados setores. Assim, por mais que o Estado se distancie do planejamento e do investimento em diversas áreas e mesmo que estabeleça uma política de cortes, não deve - e não pode - desligar-se de questões ligadas à segurança nacional.

\section{Referências bibliográficas}

ANTUNES, P. C. B. SNI \& Abin: uma leitura da atuação dos serviços secretos brasileiros ao longo do século XX. Rio de Janeiro: FGV, 2002.

BRASIL. Lei n. 2.597, de 12 de setembro de 1955. Dispõe sobre zonas indispensáveis à defesa do país e dá outras providências. Diário Oficial da República Federativa do Brasil, Brasília, 21 
set. 1955. Disponível em: <www6.senado.gov.br/legislacao/ListaTextoIntegral.action?id= 148260>. Acesso em: 20 mar. 2005.

. Ministério da Integração Nacional. Sudene. Disponível em: <www.sudene. gov.br>. Acesso em: 5 fev. 2005.

BRESSER-PEREIRA, L. C. Da administração pública burocrática à gerencial. In: BRESSERPEREIRA, L. C.; SPINK, P. (Orgs.). Reforma do Estado e administração pública gerencial. Rio de Janeiro: FGV, 2001.

CAMPANHOLE, A.; CAMPANHOlE, H. L. Constituições do Brasil. São Paulo: Atlas, 1989.

COMPANHIA SIDERÚRGICA NACIONAL. A empresa - perfil. Disponível em: <http:// csna0004.csn.com.br/portal/page?_pageid $=843,77261 \&$ dad $=$ ebiz\&_schema $=$ PORTAL $>$. Acesso em: 10 fev. 2005.

D'ARAUJO, M. C. Ainda em busca da identidade: desafios das Forças Armadas na Nova República. Rio de Janeiro: FGV, 2000.

DINIZ, E. Globalização, reforma do Estado e teoria democrática contemporânea. São Paulo Perspectiva, São Paulo, v. 15, n. 4, p. 13-22, out. 2001.

FIORI, J. L. O vôo da coruja: uma leitura não-liberal do Estado desenvolvimentista. Rio de Janeiro: EdUERJ, 1995.

FLORES, M. C. A evolução do pensamento estratégico. Revista Marítima Brasileira, Rio de Janeiro, v. 120, n. 4-6, p. 45- 61, abr./jun. 2000.

GASPARI, E. A ditadura derrotada. São Paulo: Companhia das Letras, 2003.

GUIMARÃES, C. Vargas e Kubitschek: a longa distância entre a Petrobras e Brasília. In: CARVALHO, M. A. (Org.). República do Catete. Rio de Janeiro: Museu da República, 2001.

HART, B. L. As grandes guerras da história. São Paulo: Instituição Brasileira de Difusão Cultural, 1982.

HERZ, D. A história secreta da Rede Globo. Porto Alegre: Tchê!, 1988.

HUNTINGTON, Samuel. O soldado e o Estado: teoria e política das relações entre civis e militares. Rio de Janeiro: Biblioteca do Exército, 1996.

MAGNOLI, D. Relações internacionais — teoria e história. São Paulo: Saraiva, 2004.

MATHIAS, S. K. Forças Armadas e administração pública: a participação militar nas comunicações e na educação. 1999. Tese (Doutorado) - Universidade Estadual de Campinas, Campinas. 
MELLO, V. C. Globalização e ordem internacional - a perspectiva crítica da economia política internacional. Rio de Janeiro: Iucan, 1999. (Texto para Discussão, n. 14).

MITCHELL, W. E.; SIMMONS, R. T. Para além da política: mercados, bem-estar e o fracasso da burocracia. Rio de Janeiro: Topbooks, 2003.

MOURA, A. P. P. Brasil Industrial: do capitalismo retardatário à inserção subordinada no mundo neocolonial. Bahia - Análise e Dados, Salvador, v. 11, n. 3, p. 82-89, dez. 2001.

OLIVEIRA, E. R. de; SOARES, S. A. Brasil: Forças Armadas, direção política e formato constitucional. In: D'ARAUJO, M. C.; CASTRO, C. Democracia e Forças Armadas no Cone Sul. Rio de Janeiro: FGV, 2000.

PETROBRAS. A Petrobras - história. Disponível em: <www.petrobras.com.br>. Acesso em: 10 fev. 2005.

SILVA, G. do C. e. Planejamento estratégico. Brasília: UnB, 1981.

WERNECK, L. V. O Estado Novo e a ampliação autoritária da República. In: CARVALHO, M. A. (Org.). República do Catete. Rio de Janeiro: Museu da República, 2001. 